\title{
Exploring Mechanical Alloying to Produce Doped ZnO
}

\author{
Belén Sotillo*, María Esther Solana, Paloma Fernández, \\ Dept. Física de Materiales, Fac. Físicas, U. Complutense, Ciudad Universitaria, 28040 Madrid, Spain. \\ *Correspondence: bsotillo@fis.ucm.es
}

\begin{abstract}
In this work, a mixture of $\mathrm{ZnO}$ and $\mathrm{CeO}_{2}$ powders are subjected to a milling procedure to monitor the mechanical alloying processes. $\mathrm{ZnO}-\mathrm{CeO}_{2}$ powders have been milled during 10 to 60 hours, and have been characterized by X-ray diffraction (XRD), UV-Vis absorption, Raman and photoluminescence spectroscopies, in order to study the present phases, the tensional state of material and particle sizes. The evolution of the phases presents with the time of milling, and the possible changes in the lattice parameter will help us to estimate the efficiency of the grinding process for obtaining Ce doped $\mathrm{ZnO}$.
\end{abstract}

Keywords: Mechanical Alloying; Severe Plastic Deformation; Doped ZnO

Received: May 30, 2019 Accepted: Aug 7, 2019 Online: Aug 24, 2019

\section{Introduction}

Mechanical alloying is a technique generally used in synthesis of metals and metal alloys to produce powder samples or in the form of micro or nanoparticles by cold welding, fracture, and double welding ${ }^{[1,2]}$. This technique was discovered in the decade of the 60's, when John S. Benjamin ${ }^{[2-5]}$, at the INCO laboratories, worked to achieve the hardening of nickel-based and aluminum-based alloys, by dispersion of oxides and by precipitation of the phase $\gamma$. Since then, mechanical alloy has expanded its field of application to a wide variety of alloys ${ }^{[2]}$. Its use in the processing of ceramic materials ${ }^{[1]}$ is less widespread but offers multiple advantages in various systems of technological interest and industrial applications ${ }^{[1]}$. The basic objective is to reduce the particle size to facilitate the dopant incorporation into the host lattice ${ }^{[1,2]}$. For this, the mixture of powders of the host and dopant materials is subjected to high-energy collisions $^{[6]}$. The interaction between the grinding balls and the powder particles can be characterized by processes such as cold welding, particle fragmentation and plastic deformation, until a powder is produced in which each particle is constituted by the percentage composition of the initial mix. In this way, the continuous and repeated welds produce the transformation of the material within the structure in solid state ${ }^{[6]}$.

The mechanical alloying process usually includes a ductile component that acts as a support or matrix of the other components $^{[2]}$. In this sense, the mixtures can be classified according to the ductility of the materials that intervene in three groups: ductile-ductile, ductile-fragile and fragile-fragile. In the case of ceramic materials, the process is more complex given the low ductility of most of this type of materials. However, some fine powder with a minimum of agglomerated particles, allows the precursors to create a dense baked ceramic ${ }^{[3]}$. In our case, as both starting materials are ceramic $\left(\mathrm{ZnO}\right.$ and $\left.\mathrm{CeO}_{2}\right)$, we can expect fragile-fragile behaviour. For the alloy to take place, it will be necessary for the majority component $(\mathrm{ZnO})$ to have the necessary degree of ductility for the alloy to take place. On the other hand, diffusion processes enhanced by the mechanical treatment could also favour the dopant incorporation.

A group II-VI semiconductor material, $\mathrm{ZnO}$, has been selected for the study, with great potential in various technological applications, such as gas sensors, light emitting devices (visible), blue lasers, and solar cells. It belongs to the group of metallic oxides, and is also characterized by its good photocatalytic properties, in particular when it is doped with cerium, whose oxide is precisely the material chosen as a dopant ${ }^{[1,2]}$.

Copyright (C) 2019 Belén Sotillo et al. This is an Open Access article distributed under the terms of the Creative Commons AttributionNonCommercial 4.0 International License (http://creativecommons.org/licenses/by-nc/4.0/), permitting all non-commercial use, distribution, and reproduction in any medium, provided the original work is properly cited. 


\section{Experiment}

Starting materials are commercially available $\mathrm{ZnO}$ and $\mathrm{CeO}_{2}$ powders from Sigma-Aldrich (99.9\% purity) and D'Hemio-Laboratories (chemical pure), respectively. The amount of $\mathrm{CeO}_{2}$ in the mixture is $5 \mathrm{wt} . \%$. The powder mixture is introduced in a centrifugal ball mill (Retsch S100 with grind jar and balls made of agate) and subjected to a milling process at $180 \mathrm{rpm}$ during 10,20,40 and $60 \mathrm{~h}$. Initially, $5 \mathrm{~g}$ of the mixture are introduced, and $1 \mathrm{~g}$ of the milled material is collected at the indicated milling times. The process has been carried out in atmospheric environment.

After performing the milling, the material has been characterized mainly using X-ray diffraction (XRD) and UV-Vis absorption. XRD analysis has been done by means of a Philips X'Pert PRO diffractometer using $\mathrm{Cu} \mathrm{K}$ radiation, with a step in $2 \theta$ of $0.05^{\circ}$. UV-Vis absorption studies have been performed in a Shimadzu UV-1603 spectrometer. The ZnO$\mathrm{CeO}_{2}$ powders were dispersed in ethanol to measure the absorption spectra in the range of $300-650 \mathrm{~nm}$. Additional Raman spectroscopy and photoluminescence measurements have been carried out in a confocal microscope Horiba JobinYvon LABRAM-HR to support the observations obtained with XRD and UV-Vis absorption. For measuring Raman spectra, the $633 \mathrm{~nm}$ line of a He-Ne laser is used, whereas for the photoluminescence the wavelength used to excite the sample is $325 \mathrm{~nm}$, from a He-Cd laser. A Thorlabs LMU-40x-NUV objective ( $0.5 \mathrm{NA})$ is used to both focus the laser on the powders and collect the signal. The aim of this characterization is to determine if there is incorporation of $\mathrm{Ce}$ in the $\mathrm{ZnO}$ lattice.

\section{Results and discussion}

Initially, XRD measurements have been performed on the powders of the separated materials $\left(\mathrm{ZnO}\right.$ and $\left.\mathrm{CeO}_{2}\right)$ milled during the same times $(10,20,40,60 \mathrm{~h})$ as the mixture. The recorded diffractograms are shown in Figure 1a \& 1b. For $\mathrm{ZnO}$ (Figure 1a) all the peaks are associated with the wurtzite phase of this material (ICDD card No. 01-079-5604). In the case of $\mathrm{CeO}_{2}$, the peaks found can be ascribed to cubic phases of $\mathrm{CeO}_{2}$ (ICDD card No. 04-013-4458, marked with asterisks '*' in Figure 1b) and $\mathrm{Ce}_{2} \mathrm{O}_{3}$ (ICDD card No. 04-015-1518, marked with dollars ' $\$$ ' in Figure 1b).
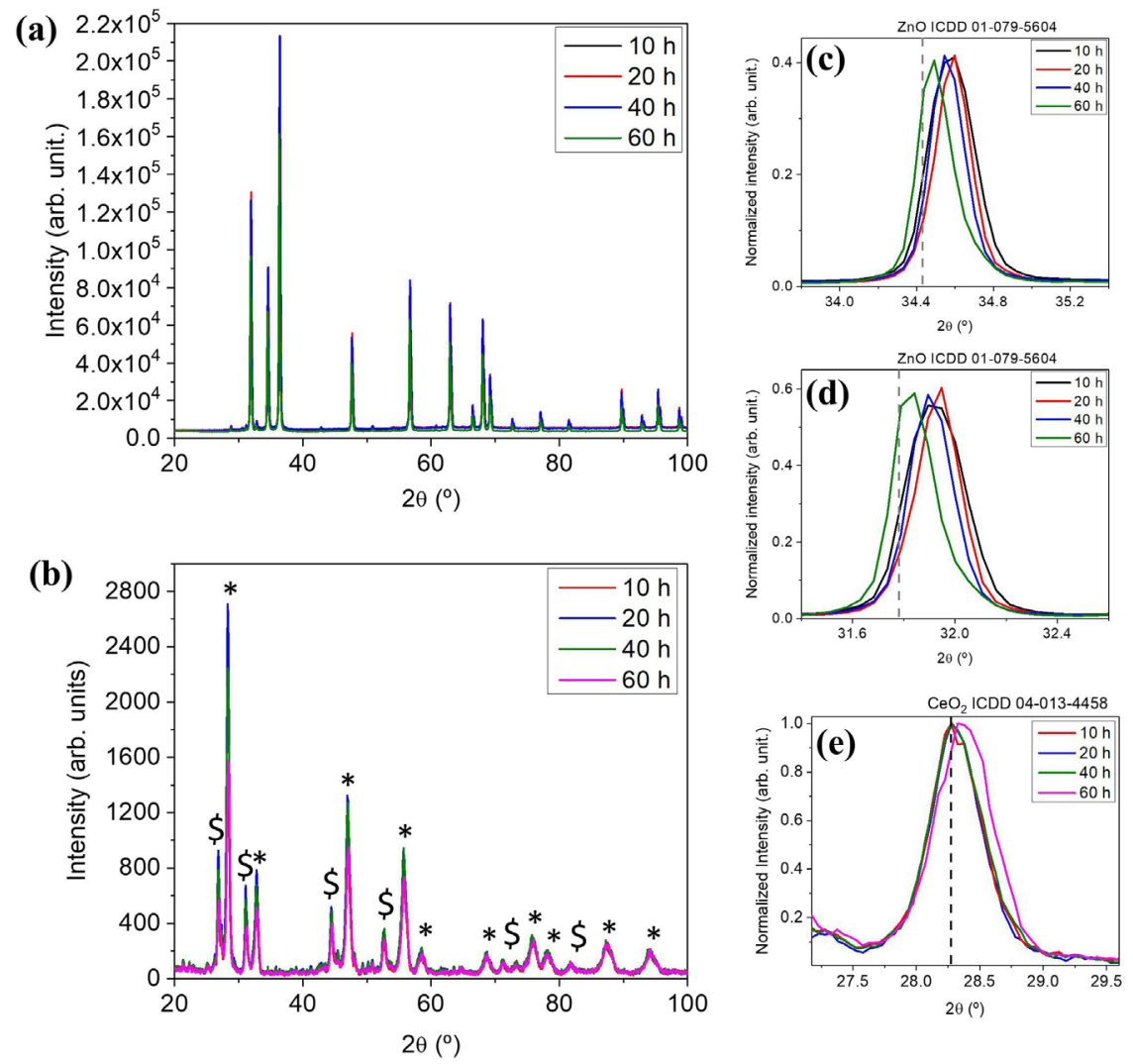

Figure 1; XRD spectra measured on: (a) pure $\mathrm{ZnO}$ milled for 10, 20, 40 and $60 \mathrm{~h}$; (b) cerium oxide milled for 10, 20, 40 and $60 \mathrm{~h}$. (c) Shift of (002) peak of pure $\mathrm{ZnO}$ for different milling times. (d) Shift of (100) peak of pure $\mathrm{ZnO}$ for different milling times. (e) Shift of pure $\mathrm{CeO}_{2}$ peak for different milling times. 
In the case of $\mathrm{ZnO}$, a change in the position of the peaks is noticed. This effect is presented, for the (002) and (100) reflections, in Figure 1c \& 1d. It is seen that, for the lower milling times $(10-20 \mathrm{~h})$ the peaks are shifted towards higher angles respect to the values in the ICDD card. This is related to a decrease in the lattice parameters, an indication of the presence of residual compression stress. For longer milling times $(40 \mathrm{~h})$ and especially for $60 \mathrm{~h}$, a relaxation of the residual stresses is produced, evidenced by the tendency of the peaks to return to the unstressed position. This relaxation could be related to a self-annealing occurred at the longest milling times, hence the larger amount of deposited energy. In table 1 are shown the lattice parameters, calculated from the position of the peaks using Bragg's law and the plane spacing for hexagonal crystal lattice:

$$
\begin{aligned}
& 2 d_{h k l} \sin \theta=n \lambda \\
& \frac{1}{d_{h k l}^{2}}=\frac{4}{3}\left(\frac{h^{2}+h k+k^{2}}{a^{2}}\right)+\frac{l^{2}}{c^{2}}
\end{aligned}
$$

Where:

$\mathrm{d}_{\mathrm{hkl}}$ is the plane spacing for (hkl) planes, $\theta$ is the angle of the diffracted peak, $\lambda$ is the wavelength used to measure the diffraction, and ' $a$ ' and ' $c$ ' are the lattice parameters. In table 1 is again clearly visible the decrease in the dimension of both parameters a and c of the wurtzite structure for milling times of 10 and $20 \mathrm{~h}$, and the increase of these parameters for 40 and $60 \mathrm{~h}$.

\begin{tabular}{|l|l|l|l|l|}
\hline & \multicolumn{2}{|l|}{ Parameter a } & Parameter c \\
\hline & Peak (100) position & Calculated value & Peak (002) position & Calculated value \\
\hline ZnO ICDD 01-079-5604 & $31.7820^{\circ}$ & $0.32484 \mathrm{~nm}$ & $34.4300^{\circ}$ & $0.52053 \mathrm{~nm}$ \\
\hline Milled 10 h & $31.9088^{\circ}$ & $0.32358 \mathrm{~nm}$ & $34.5651^{\circ}$ & $0.51856 \mathrm{~nm}$ \\
\hline Milled 20 h & $31.9398^{\circ}$ & $0.32328 \mathrm{~nm}$ & $34.5925^{\circ}$ & $0.51816 \mathrm{~nm}$ \\
\hline Milled 40 h & $31.9058^{\circ}$ & $0.32361 \mathrm{~nm}$ & $34.5563^{\circ}$ & $0.51869 \mathrm{~nm}$ \\
\hline Milled 60 h & $31.8323^{\circ}$ & $0.32434 \mathrm{~nm}$ & $34.4870^{\circ}$ & $0.51970 \mathrm{~nm}$ \\
\hline
\end{tabular}

Table 1. Pure $\mathrm{ZnO}$ lattice parameters calculated from diffraction peaks position

Changes in the diffraction peaks of $\mathrm{CeO}_{2}$ are less pronounced (Figure 2c \& 2d). For 10, 20 and $40 \mathrm{~h}$ milling times, there is no shift of the peaks from the unstressed position. It is just for $60 \mathrm{~h}$ when a slight shift towards higher angles is noticed, indication of compression stress induced in the crystal lattice. The minor effect in this case would be related to the higher hardness of ceria.

Once, the effect of the milling process in both materials has been studied separately, the results obtained for the mixture 95 wt. $\% \mathrm{ZnO}+5$ wt. $\% \mathrm{CeO}_{2}$ can be analyzed. Firstly, it is observed that the diffraction peaks for the mixture are shifted towards lower angles, in comparison with the position of the peaks of milled $\mathrm{ZnO}$. As an example, in Figure 2a \& $\mathbf{2 b}$, are presented the shifts of some peaks (corresponding to (002) and (101) reflections) for $10 \mathrm{~h}$ and $40 \mathrm{~h}$ milling times. As it has been done for pure $\mathrm{ZnO}$, the values for ' $a$ ' and ' $c$ ' are the lattice parameters can be calculated for the mixture, and the results are shown in Table 2. Comparison of lattice parameters for $\mathrm{ZnO}$ and $\mathrm{ZnO}+\mathrm{CeO}_{2}$ is presented in Figure 2c \& 2d, where it is visible that the $\mathrm{ZnO}$ lattice parameters are less compressed in the mixture for milling times of 10, 20 and $40 \mathrm{~h}$. This effect is consistent with the incorporation of Ce in the $\mathrm{ZnO}$ lattice, occupying $\mathrm{Zn}$ positions, since $\mathrm{Ce}$ ionic radius is bigger that than of $\mathrm{Zn}(\mathrm{Ce}(\mathrm{III})=101 \mathrm{pm}$ and $\mathrm{Ce}(\mathrm{IV})=87 \mathrm{pm}$ versus $\mathrm{Zn}(\mathrm{II})=60$ $\mathrm{pm})^{[9]}$. Then, the incorporation of $\mathrm{Ce}$ will produce an expansion of the $\mathrm{ZnO}$ lattice ${ }^{[10]}$ that will compete with the compression that is being produced in the milling process. In other words, there is a competition between the incorporation of $\mathrm{Ce}$ (which will produce an increase of the lattice parameter) and the compression (decrease of lattice parameter) induced by the milling process. Although cerium oxide related peaks are still present in the diffractograms, this is an indication that a portion of cerium in the mixture has been incorporated to the $\mathrm{ZnO}$ lattice.

The presence of Cerium in the milling process also affects the relaxation of the $\mathrm{ZnO}$ lattice observed for longer milling times. As can be seen in Figure $2 \mathrm{c} \& 2 \mathrm{~d}$, for $60 \mathrm{~h}$, the lattice parameters show more compression (compared with the unstressed lattice) for the $\mathrm{ZnO}-\mathrm{CeO}_{2}$ mixture, opposite from the behaviour observed for 10, 20, and $40 \mathrm{~h}$. Then, $\mathrm{Ce}$ incorporation stops the $\mathrm{ZnO}$ to relax the stresses induced in the milling, again likely due to the stress induced by the difference in radii. 

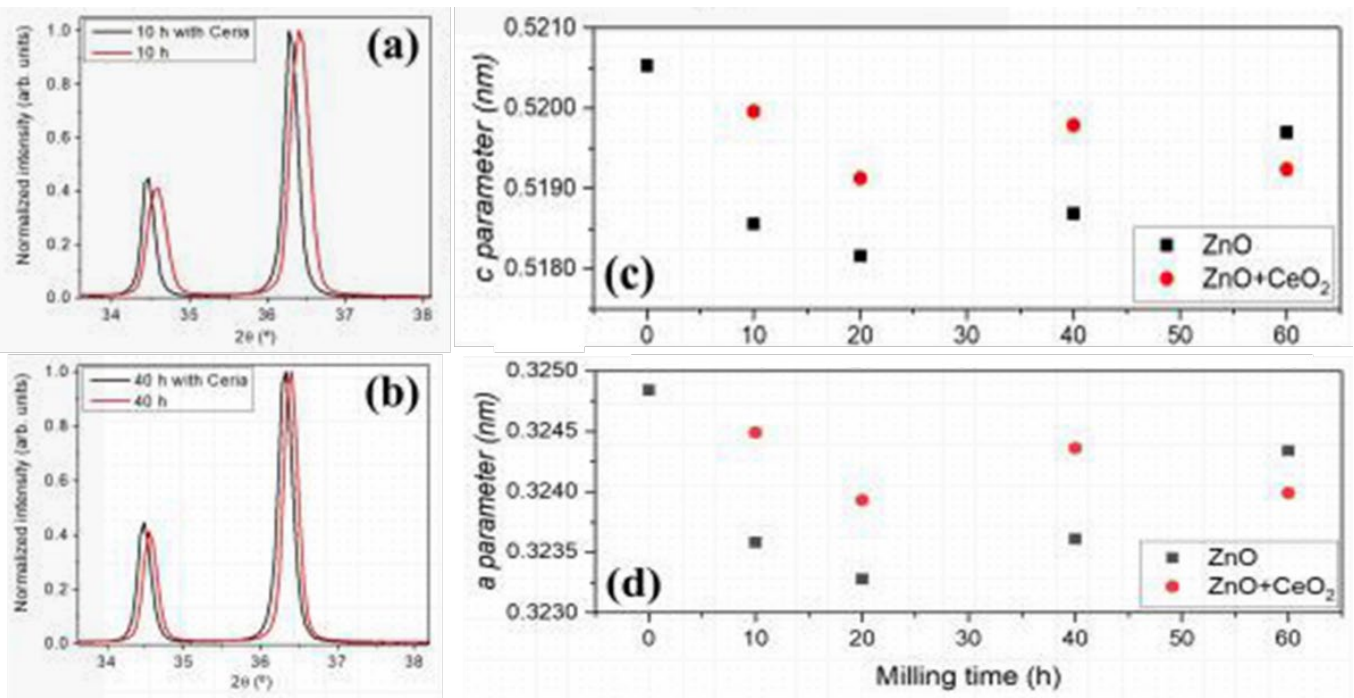

Figure 2. Comparison of (002) and (101) $\mathrm{ZnO}$ diffraction peaks in pure and Ce doped material: (a) milled for $10 \mathrm{~h}$; (b) milled for 40 h. Evolution of $\mathrm{ZnO}$ (c) c parameter and (d) a parameter with milling time.

\begin{tabular}{|l|l|l|l|l|}
\hline & \multicolumn{2}{|l|}{ Parameter a } & Parameter c \\
\hline & Peak (100) position & Calculated value & Peak (002) position & Calculated value \\
\hline $\mathrm{ZnO}$ ICDD 01-079-5604 & $31.7820^{\circ}$ & $0.32484 \mathrm{~nm}$ & $34.4300^{\circ}$ & $0.52053 \mathrm{~nm}$ \\
\hline Milled 10 h $+\mathrm{CeO}_{2}$ & $31.8175^{\circ}$ & $0.32449 \mathrm{~nm}$ & $34.4690^{\circ}$ & $0.51996 \mathrm{~nm}$ \\
\hline Milled 20 $\mathrm{h}+\mathrm{CeO}_{2}$ & $31.8739^{\circ}$ & $0.32393 \mathrm{~nm}$ & $34.5263^{\circ}$ & $0.51913 \mathrm{~nm}$ \\
\hline Milled 40 $\mathrm{h}+\mathrm{CeO}_{2}$ & $31.8301^{\circ}$ & $0.32436 \mathrm{~nm}$ & $34.4808^{\circ}$ & $0.51979 \mathrm{~nm}$ \\
\hline Milled 60 h+CeO 2 & $31.8677^{\circ}$ & $0.32399 \mathrm{~nm}$ & $34.5185^{\circ}$ & $0.51924 \mathrm{~nm}$ \\
\hline
\end{tabular}

Table 2. Doped $\mathrm{ZnO}$ lattice parameters calculated from diffraction peaks position

Finally, a Williamson-Hall analysis ${ }^{[5]}$ has been performed. In this model, the broadening of the diffraction peaks is considered to come from the small crystallite size and the presence of non-uniform micro-strain ${ }^{[6]}$. Then, this analysis connects the width of the diffraction peaks $\left(\beta_{\mathrm{hkl}}\right)$ with the residual strain $(\varepsilon)$ and the crystalline size (D) as follows:

$$
\beta_{h k l} \cdot \cos \theta=\frac{k}{\lambda D}+4 \varepsilon \sin \theta
$$

Where $\mathrm{k}$ is an empirical constant with a typical value of $0.94^{[11]}$. Preforming a linear regression of the data from the diffraction peaks, we can the estimate the values of $\mathrm{D}$ and $\varepsilon$. Although some discrepancies are found in several diffraction peaks, the general tendency fits well to the linear behaviour, and let us conclude that the crystallite size is similar for both milled $\mathrm{ZnO}$ and $\mathrm{ZnO}+\mathrm{CeO}_{2}$, in the range of $30-35 \mathrm{~nm}$, for all the milling times. On the other hand, the strain for $\mathrm{ZnO}$ is around $-7 \times 10^{-4}$ (compressive), whereas for $\mathrm{ZnO}+\mathrm{CeO}_{2}$ is around $-6 \times 10^{-4}$. In agreement with the discussion above, $\mathrm{Ce}$ incorporation (which produces an expansion of $\mathrm{ZnO}$ lattice) is competing with compression stress induced in the milling process.

The observations from XRD measurements are in agreement with the Raman spectra (Figure 3). For the sake of clarity, we will focus on the spectra for pure and doped $\mathrm{ZnO}$ milled for $60 \mathrm{~h}$. In the Raman spectra recorded on milled $\mathrm{ZnO}$ (Figure 3a) peaks are detected at 100 ( $\left.\mathrm{E}_{2}(\mathrm{low})\right), 205$ (multiple-phonon mode), 333 ( $\mathrm{E}_{2}$ (high)- $\left.\mathrm{E}_{2}(\mathrm{low})\right), 382\left(\mathrm{~A}_{1}(\mathrm{TO})\right.$ ), 410 ( $\left.\mathrm{E}_{1}(\mathrm{TO})\right), 439$ ( $\mathrm{E}_{2}$ (high)), 538 (multiple-phonon mode), 584 ( $\left.\mathrm{E}_{1}(\mathrm{LO})\right), 665$ (multiple-phonon mode), 1100 (multiple-phonon mode) and $1150 \mathrm{~cm}^{-1}$ (multiple-phonon mode), ascribed to the expected Raman modes in $\mathrm{ZnO}^{[13]}$. These peaks also appear in the spectra of the doped mixture (Figure 3b, along with some extra peaks located at 452 and $564 \mathrm{~cm}^{-1}$, which can be associated to $\mathrm{CeO}_{2}$ (F2g mode and defect-induced (D) mode, respectively) ${ }^{[14]}$. As pointed out in the XRD analysis, $\mathrm{CeO}_{2}$ peaks are detected along with the $\mathrm{ZnO}$ ones, showing that not all the cerium is incorporated to the $\mathrm{ZnO}$ lattice. However, in the Raman spectra there are some evidences of incorporation of Ce. First, the Raman modes show a slight increase in width, associated with the disorder in the lattice induced by the incorporation of the dopant. Moreover, a change in the relative intensity of the $\mathrm{E}_{2}$ (high) and $\mathrm{E}_{2}$ (low) modes is clearly observed. $\mathrm{E}_{2}$ (high) is mostly related to the oxygen vibration in the $\mathrm{ZnO}$ crystal lattice, whereas $\mathrm{E}_{2}$ (low) originated from 
the $\mathrm{Zn}$ sublattice vibrations ${ }^{[12]}$. The decrease of the relative intensity of the $\mathrm{E}_{2}(\mathrm{low})$ and increase in width indicates the incorporation of $\mathrm{Ce}$ in $\mathrm{Zn}$ position.

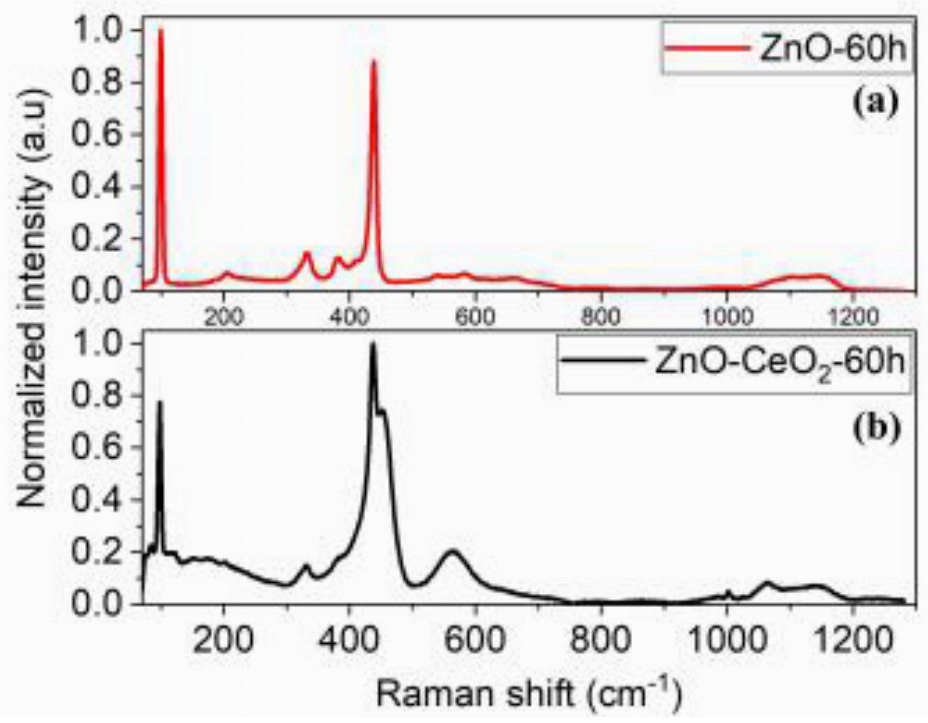

Figure 3; Raman spectra $\left(\lambda_{\text {exc }}=633 \mathrm{~nm}\right.$ ) recorded on: (a) $\mathrm{ZnO}$ milled for $60 \mathrm{~h}$; (b) mixture $\mathrm{ZnO}+\mathrm{CeO}_{2}$ milled for $60 \mathrm{~h}$.

The effect of the incorporation of $\mathrm{Ce}$ in the $\mathrm{ZnO}$ crystal lattice is also observed in the UV-Vis absorption measurements. In semiconductor materials, the absorption strength depends on the photon energy (hv) and the bandgap $\left(\mathrm{E}_{\mathrm{g}}\right)$ of the material as follows (as described by Davis and Mott ${ }^{[9]}$ ):

$$
(a h v)^{1 / n}=A\left(h v-E_{g}\right)
$$

Where: $\alpha$ is the absorption coefficient; $\mathrm{n}$ is a number that depends on the nature of the electronic transition.

For $\mathrm{ZnO}$, we would have direct allowed transitions, so $\mathrm{n}=1 / 2$. Following this model, if (ahv) ${ }^{2}$ is plotted versus the photon energy hv (the so-called Tauc plot), the $\mathrm{E}_{\mathrm{g}}$ value can be extracted from the $\mathrm{X}$-axis interception of the linear region of this plot (Figure 4a, $\mathbf{4 b}$ ). In Figure 4a it is clearly visible that the milling process does not affect the $E_{\mathrm{g}}$ of pure $\mathrm{ZnO}\left(\mathrm{E}_{\mathrm{g}}=3.12 \mathrm{eV}\right)$. However, when $\mathrm{Ce}$ is incorporated, there is a shift of $\mathrm{E}_{\mathrm{g}}$ towards lower energies (Figure $\left.4 \mathbf{b}\right)$. The change in $\mathrm{E}_{\mathrm{g}}$ with milling time for both pure and doped material is shown in Figure 4d. Due to the low level of Ce incorporation expected, the red-shift observed in the $\mathrm{ZnO}$ bandgap is associated with the introduction of shallow defect levels near the edge of the conduction or valence bands.
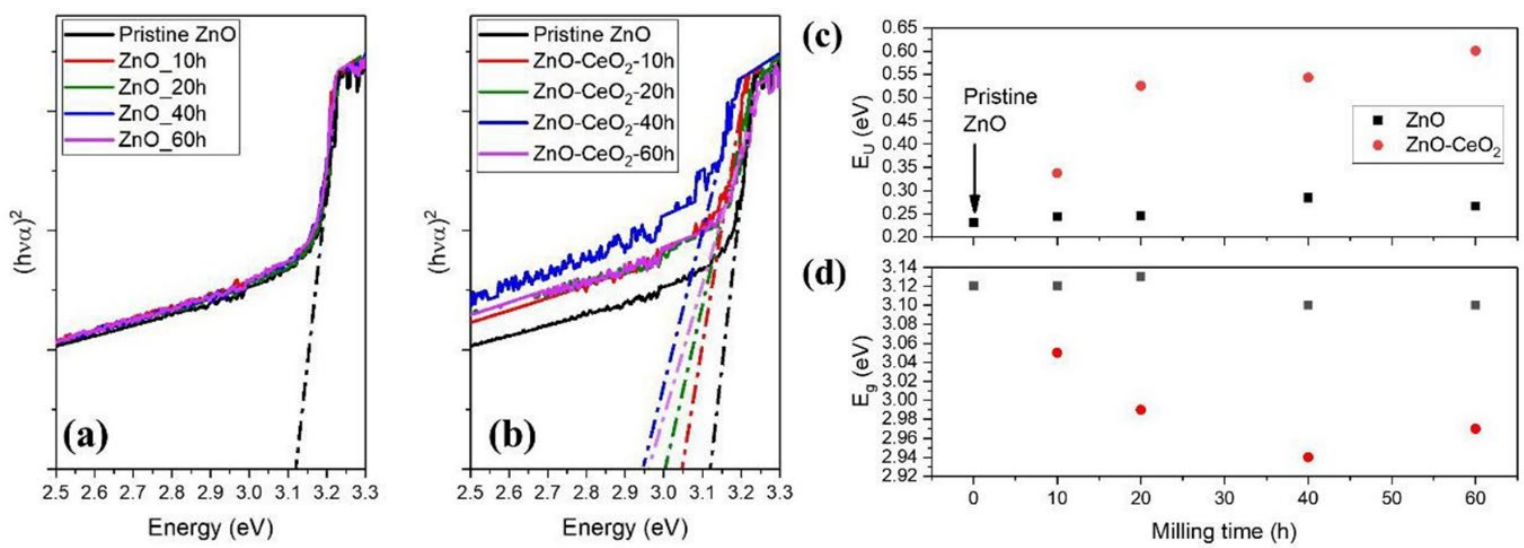

Figure 4. Tauc plot of (a) pure $\mathrm{ZnO}$ and (b) Ce doped $\mathrm{ZnO}$ for different milling times. (c) Variation of Urbach energy (EU) with milling times for pure (black squares) and doped (red circles) $\mathrm{ZnO}$. (d) Variation of bandgap ( $\mathrm{E}_{\mathrm{g}}$ ) with milling times for pure (black squares) and doped (red circles) $\mathrm{ZnO}$.

From the measured absorption spectra, the Urbach energy $\left(\mathrm{E}_{\mathrm{U}}\right)$ can also be calculated. Where $\alpha$ varies exponentially with photon energy, it is possible to assume that the spectral dependence of the absorption edge follows the Urbach formula $^{[10]}$ : 


$$
\alpha(h v)=\alpha_{0} \exp \left(\frac{h v-E_{0}}{E_{U}}\right)
$$

By plotting $\ln (a)$ versus the photon energy $h v$, the value of $E_{U}$ can be calculated from the slope of the linear region. The obtained values are presented in Figure 4c. For pure $\mathrm{ZnO}$, there is an increase of the Urbach energy with the milling time, from $0.23 \mathrm{eV}$ for the pristine material to $0.27 \mathrm{eV}$ for $60 \mathrm{~h}$ milling. On the other hand, the increase of Urbach energy is stronger for the Ce doped $\mathrm{ZnO}$, reaching a value of $0.60 \mathrm{eV}$. Comparing both results, it is clear that, although the milling process is introducing some degree of disorder in the $\mathrm{ZnO}$ crystal lattice, is the incorporation of Ce which induces a higher disorder, confirming the inclusion of the dopant in the $\mathrm{ZnO}$ lattice.

Finally, the PL measurements done on the mixture powders support the UV-Vis absorption results. Pure ZnO has the near band edge emission (NBE) centered at $3.2 \mathrm{eV}$, whereas for doped $\mathrm{ZnO}$ it is centered at $3.0 \mathrm{eV}$. Also, the NBE band is broader for the doped material. The smaller band gap in $\mathrm{CeO}_{2}$ (around $3.02 \mathrm{eV}$ ) could be responsible for this shift and broadening of the near band edge emission.

(a)

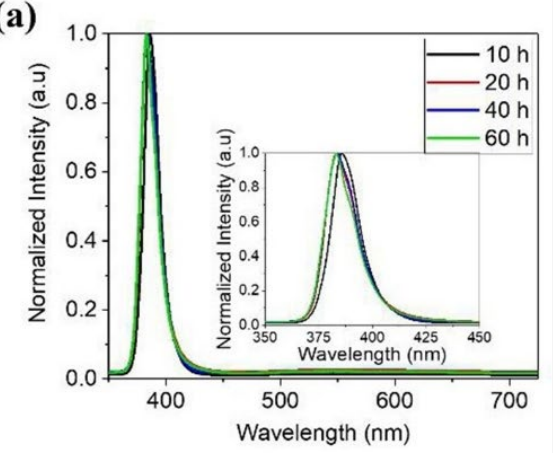

(b)

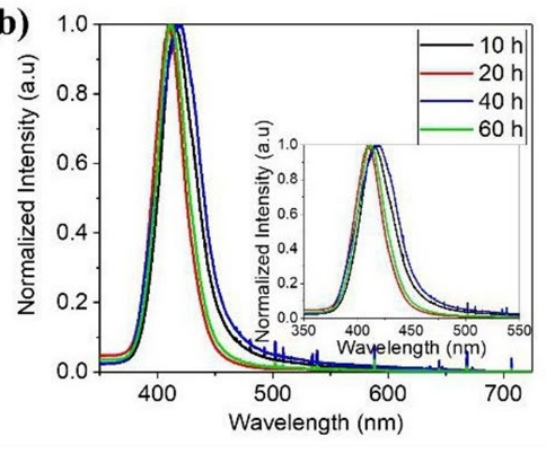

Figure 5. Photoluminescence (PL) spectra $\left(\lambda_{\mathrm{exc}}=325 \mathrm{~nm}\right.$ ) recorded on: (a) $\mathrm{ZnO}$ milled for 10, 20, 40 and $60 \mathrm{~h}$;

(b) mixture $\mathrm{ZnO}+\mathrm{CeO}_{2}$ milled for 10, 20, 40 and $60 \mathrm{~h}$.

\section{Conclusions}

This study opens a clear route to produce doped $\mathrm{ZnO}$ without the necessity of high energy attrition mills nor high temperatures. We have studied the incorporation of $\mathrm{Ce}$ in $\mathrm{ZnO}$ by means of a mechanical process. The competition between the compressive stresses associated to deformation process and tensile strain induced by Ce incorporation are responsible for the observed behaviour. Despite the brittleness of both ceramic materials, the incorporation of Ce in the $\mathrm{ZnO}$ lattice is evident from the experiments. Fast diffusion paths associated to defects induced during milling process could play an important role on the dopant incorporation.

\section{Acknowledgements}

Spanish Ministry Economy, Industry and Competitiveness MINECO/FEDER-MAT2015-65274-R Project. B. Sotillo acknowledges financial support from Comunidad de Madrid (Ayudas del Programa de Atracción de Talento). The authors would like to thank the UCM CAI of X-Ray diffraction for performing the XRD measurements.

\section{References}

1. Sharma, P., Sharma, S., \&amp; Khanduja, D. (2015). On the use of ball milling for the production of ceramic powders. Materials and Manufacturing Processes, 30(11), 1370-1376.

2. Suryanarayana, C. (2001). Mechanical alloying and milling. Progress in materials science, 46(1-2), 1-184.

3. Forrester, J. S., Zobec, J. S., Phelan, D., \&amp; Kisi, E. H. (2004). Synthesis of PbTiO3 ceramics using mechanical alloying and solid-state sintering. Journal of Solid State Chemistry, 177(10), 3553-3559.

4. Wongmaneerung, R., Yimnirun, R., \&amp; Ananta, S. (2006). Effects of milling time and calcination condition on phase formation and particle size of lead titanate nanopowders prepared by vibro-milling. Materials Letters, 60(21-22), 2666-2671.

5. Canakci, A., Erdemir, F., Varol, T., \&amp; Patir, A. (2013). Determining the effect of process parameters on particle size in mechanical milling using the Taguchi method: measurement and analysis. Measurement, 46(9), 3532-3540.

6. Suñol Martínez, J. J., \&amp; Fort, J. (2008). Materials developed by mechanical alloying and melt spinning. (C) International Review of Physics, 2008, vol. 2, núm. 1, p. 31-35. 
7. Faisal, M., Ismail, A. A., Ibrahim, A. A., Bouzid, H., \&amp; Al-Sayari, S. A. (2013). Highly efficient photocatalyst based on Ce doped $\mathrm{ZnO}$ nanorods: Controllable synthesis and enhanced photocatalytic activity. Chemical engineering journal, 229, 225-233.

8. Karunakaran, C., Gomathisankar, P., \&amp; Manikandan, G. (2010). Preparation and characterization of antimicrobial Ce-doped $\mathrm{ZnO}$ nanoparticles for photocatalytic detoxification of cyanide. Materials Chemistry and Physics, 123(2-3), 585-594. http://abulafia.mt.ic.ac.uk/shannon/ptable.php

9. Urbieta, A., Fernández, P., \&amp; Piqueras, J. (2012). Nanowires and stacks of nanoplates of Mn doped ZnO synthesized by thermal evaporation-deposition. Materials Chemistry and Physics, 132(2-3), 1119-1124.

10. Williamson, G. K., \&amp; Hall, W. H. (1953). X-ray line broadening from filed aluminum and wolfram. Acta metallurgica, 1(1), 22-31.

11. Zak, A. K., Majid, W. A., Abrishami, M. E., \&amp; Yousefi, R. (2011). X-ray analysis of ZnO nanoparticles by Williamson-Hall and size-strain plot methods. Solid State Sciences, 13(1), 251-256.

12. Cuscó, R., Alarcón-Lladó, E., Ibanez, J., Artús, L., Jimenez, J., Wang, B., \&amp; Callahan, M. J. (2007). Temperature dependence of Raman scattering in ZnO. Physical Review B, 75(16), 165202.

13. Wu, Z., Li, M., Howe, J., Meyer III, H. M., \&amp; Overbury, S. H. (2010). Probing defect sites on CeO2 nanocrystals with well-defined surface planes by Raman spectroscopy and O2 adsorption. Langmuir, 26(21), 16595-16606.

14. Davis, E. A., \&amp; Mott, N. (1970). Conduction in non-crystalline systems V. Conductivity, optical absorption and photoconductivity in amorphous semiconductors. Philosophical Magazine, 22(179), 0903-0922.

15. Hvedstrup Jensen, G., \&amp; Skettrup, T. (1973). Absorption edge and urbach's rule in ZnO. physica status solidi (b), 60(1), 169-173. 